\title{
Flame Inhibition by Ferrocene, Carbon Dioxide, and Trifluoromethane Blends: Synergistic and Antagonistic Effects
}

Gregory T. Linteris and Marc D. Rumminger

Building and Fire Research Laboratory

Gaithersburg, Maryland 20899

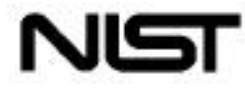

United States Department of Commerce

Technology Administration

National Institute of Standards and Technology 


\section{Flame Inhibition by Ferrocene, Carbon Dioxide, and Trifluoromethane Blends: Synergistic and Antagonistic Effects}

Gregory T. Linteris and Marc D. Rumminger

October, 1999

Building and Fire Research Laboratory

National Institute of Standards and Technology

Gaithersburg, MD 20899

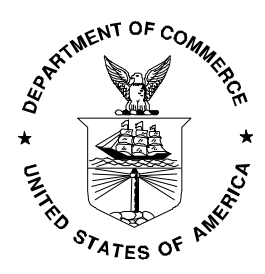

U.S. Department of Commerce

William M. Daley, Secretary

Technology Administration

Gary Bachula, Acting Under Secretary for Technology

National Institute of Standards and Technology

Raymond G. Kammer, Director 


\title{
Flame Inhibition by Ferrocene, Carbon Dioxide, and Trifluoromethane Blends: Synergistic and Antagonistic Effects
}

\author{
G.T. Linteris and M.D. Rumminger \\ National Institute of Standards and Technology \\ Gaithersburg, MD 20899-8651; linteris@ nist.gov; mrum@asme.org \\ (current address for MDR: Sandia National Laboratories; MS 9052; Livermore, CA 94551)
}

Chemical and Physical Processes in Combustion, October 11-13, 1999

Eastern States Section Meeting, The Combustion Institute, North Carolina State University, Raleigh, NC

The production of $\mathrm{CF}_{3} \mathrm{Br}$ has been banned. As a flame inhibitor, iron pentacarbonyl $\left(\mathrm{Fe}(\mathrm{CO})_{5}\right)$ is about two orders of magnitude more efficient than $\mathrm{CF}_{3} \mathrm{Br}$, but it is flammable and highly toxic, and its addition to premixed flames at mole fractions above a few hundred ppm does not further reduce the burning velocity. If other iron compounds can be identified which show the same strong inhibition but are less toxic and don't lose their effectiveness, they may find use in fire suppressants. Ferrocene $\left(\mathrm{Fe}\left(\mathrm{C}_{5} \mathrm{H}_{5}\right)_{2}\right.$ or $\left.\mathrm{Fec}\right)$ modifies the sooting tendency of flames, is added to materials as a flame retardant and is an antiknock agent. It is far less toxic than $\mathrm{Fe}(\mathrm{CO})_{5}$, and it may produce the same iron-containing intermediates. Here, we present the first measurements of flame inhibition by ferrocene, compare it with $\mathrm{Fe}(\mathrm{CO})_{5}$ and $\mathrm{CF}_{3} \mathrm{Br}$, and present data showing how combining it with other compounds can overcome the loss in effectiveness experienced by both it and $\mathrm{Fe}(\mathrm{CO})_{5}$.

Flame inhibition by bromine, alkali metals, and transition metals have been described in the literature, and their reduced effectiveness at higher mole fractions has been discussed in detail [1-3]. Since the chemicals are believed to act through homogeneous gas-phase catalytic radical recombination cycles, the inhibition mechanism requires a radical superequilibrium to be most effective. Consequently, once radicals are reduced to equilibrium levels via inhibitor addition, further reduction in the overall reaction rate from additional inhibitor is minimal. This loss in effectiveness due to radicals approaching their equilibrium values has been demonstrated for increasing mole fraction of inhibitor in calculations employing both an idealized "perfect" inhibitor [2] and $\mathrm{Fe}(\mathrm{CO})_{5}$ [3], and has been discussed by Rosser et al. [4] and Hastie [5]. Nonetheless, the measured loss in effectiveness of $\mathrm{Fe}(\mathrm{CO})_{5}$ occurs at a lower mole fraction than expected based on these calculations; the actual cause appears to be condensation of iron compounds and the resulting limit to the gas-phase iron-species concentrations [6]. Regardless of the cause of the loss of effectiveness, previous researchers [4,5,7-10] have suggested that combinations of thermally acting and catalytic agents might prove beneficial. The effectiveness of iron pentacarbonyl in premixed flames has been shown to be greatly increased at lower oxygen mole fraction, and the effect has been attributed to the larger superequilibrium ratio (the peak radical mole fraction divided by the equilibrium value) which exists at lower oxygen mole fraction [1]. In contrast, the effectiveness of relatively inert agents such as $\mathrm{N}_{2}$ and $\mathrm{CO}_{2}$ is not a strong function of the oxygen mole fraction in the oxidizer stream, $X_{O 2, o x}$. (In the present work we find that addition of $10 \% \mathrm{CO}_{2}$ to flames with $X_{O 2, o x}$ equal to either 0.21 or 0.244 reduces the normalized burning velocity by about half, whereas $\mathrm{Fe}(\mathrm{CO})_{5}$ is more than twice as effective for $X_{O 2, o x}=0.21$ than for 0.244 [1]). (Note that all references to percent and ppm in the present work are on a volume basis.) Since adding a thermal agent raises the superequilibrium ratio, the possibility exists for very effective blends of catalytically and thermally acting agents. Consequently, we report here the burning velocity of premixed flames in the presence of combinations of a thermal agent $\mathrm{CO}_{2}$, (which does not lose its effectiveness at higher mole fraction) and catalytic agents (which are superbly effective at low inhibitor mole fraction).

The premixed laminar flame speed $\mathrm{S}_{\mathrm{L}}$ provides a measure of the effect of the inhibitor on the overall reaction rate. The experimental arrangement, described in detail previously $[1,10,11]$, has been modified only to accommodate a new evaporator for ferrocene and heating of the gas lines and burner tube. A Mache-Hebra nozzle burner (1.0 $\mathrm{cm} \pm 0.05 \mathrm{~cm}$ diameter) produces a premixed Bunsen-type flame about $1.3 \mathrm{~cm}$ tall with a straight sided schlieren image which is captured by a frame-grabber board in a PC. Digital mass flow controllers hold the equivalence ratio $\phi, X_{O 2, o x}$, and the flame height constant while maintaining the inlet mole fraction of the inhibitor $X_{i n}$ at the desired value. The inhibitors are $\mathrm{N}_{2}, \mathrm{CF}_{3} \mathrm{H}, \mathrm{CO}_{2}, \mathrm{Fec}$, and $\mathrm{Fe}(\mathrm{CO})_{5}$. The average burning velocity is determined from the reactant flows and the schlieren image using the total area method. As in earlier research, the fuel gas is 
methane (Matheson ${ }^{1}$ UHP, 99.9\%), and the oxidizer stream consists of nitrogen (boil-off from liquid $\mathrm{N}_{2}$ ) and oxygen (MG Industries, $\mathrm{H}_{2} \mathrm{O}<50 \mathrm{ppm}$, and total hydrocarbons $<5 \mathrm{ppm}$ ). The inhibitors used are Fec (Aldrich, 98\%), $\mathrm{Fe}(\mathrm{CO})_{5}$ (Aldrich), $\mathrm{CF}_{3} \mathrm{Br}$ (Great Lakes), $\mathrm{N}_{2}$, and $\mathrm{CO}_{2}$ (Airgas). The $\mathrm{Fe}(\mathrm{CO})_{5}$ is added to $\mathrm{N}_{2}$ carrier gas using a two-stage saturator in an ice bath. Because the vapor pressure of Fec is much lower than that of iron pentacarbonyl, Fec addition at mole fractions up to $500 \mathrm{ppm}$ requires both higher bath temperature $\left(70^{\circ}\right.$ to $80^{\circ} \mathrm{C}$, held within $0.01{ }^{\circ} \mathrm{C}$ ) and higher nitrogen carrier gas flow rates (up to $350 \mathrm{~cm}^{3} / \mathrm{min}$ ) relative to $\mathrm{Fe}(\mathrm{CO})_{5}$. Also, the solid state of Fec requires an evaporator with larger surface areas for heat and mass transfer. Our evaporator design, based upon that of Megaridis [12], has a $30 \pm 5 \mathrm{~cm}^{3}$ packed bed (to provide the bulk of the ferrocene), followed by thirty sublimation stages (to insure that the carrier gas is saturated at the bath temperature); each stage consists of a $5 \mathrm{~mm}$ layer of ferrocene, $2.36 \mathrm{~cm}$ in diameter, on a 60 mesh stainless screen and a $4 \mathrm{~mm}$ gap. Temperature controllers maintain the transfer lines at $(80 \pm 3){ }^{\circ} \mathrm{C}$ and the burner tube at $(80 \pm 1){ }^{\circ} \mathrm{C}$. For all flames, the equivalence ratio (in the absence of inhibitor) is 1.0, and agent mole fraction is calculated relative to the reactant total without the inhibitor.

The experimental burning velocity reduction caused by the addition of $\mathrm{Fec}$ and $\mathrm{Fe}(\mathrm{CO})_{5}$ to the stoichiometric methane flames are presented in Figure 1. Data are plotted as normalized burning velocity, which is the burning velocity of the inhibited flame divided by the value for the same flame in the absence of inhibitor. (For Figs. 1 to 4, the solid lines are fits to the data.) As Figure 1 shows, Fec (closed symbols) reduces the burning velocity as effectively as does $\mathrm{Fe}(\mathrm{CO})_{5}$ (open symbols), and it does not appear to lose its effectiveness until higher mole fraction. As with $\mathrm{Fe}(\mathrm{CO})_{5}$, the magnitude of the inhibition is strongly dependent upon the oxygen mole fraction in the oxidizer, with oxygen-deprived flames inhibited much more strongly.

Figure 2 presents experimental data for addition of pure $\mathrm{CO}_{2}$ (or pure $\mathrm{N}_{2}$ ) and $\mathrm{CO}_{2} / \mathrm{Fec}$ blends at four values of the equivalent percentage of $\mathrm{Fec}$ in $\mathrm{CO}_{2}: 0,0.053 \%, 0.2 \%$, and $0.54 \%$. The last data point in a series represents the maximum value of $X_{i n}$ at which a flame could be stabilized. The blends of the inert and chemically acting agents are shown to be highly effective. Addition of about $10 \%$ of pure $\mathrm{CO}_{2}$ (or $25 \%$ pure $\mathrm{N}_{2}$ ) reduces $\mathrm{S}_{\mathrm{L}}$ by a factor of two. Addition of the equivalent of $0.1 \% \mathrm{Fec}$ to $\mathrm{CO}_{2}$ reduces the required $\mathrm{CO}_{2}$ by about a factor of two, and $0.6 \% \mathrm{Fec}$ reduces the required $\mathrm{CO}_{2}$ by ten, making this blend about as effective as $\mathrm{CF}_{3} \mathrm{Br}$ (for which addition of about $1 \%$ halves the burning velocity). It is important to note that the flames with $\mathrm{CO}_{2} / \mathrm{Fec}$ combinations in Figure 2 do not display the large loss in effectiveness, i.e., the plateau region, occurring in most of the curves in Figure 1. Although one might expect the slightly cooler, slower flames with added $\mathrm{CO}_{2}$ to have more condensation of iron species, the greater efficiency of the catalytic cycle in the diluted flames predominates.

Other compounds may be convenient for blending with catalytic agents. Hydrofluorocarbons are of interest since they are presently used as halon replacements. These compounds have been found to reduce the burning velocity of premixed methane-air flames by reducing peak $\mathrm{H}$-atom mole fractions through reactions forming $\mathrm{HF}$ and by lowering the temperature of the flame. Since they have also been shown to reduce the equilibrium mole fractions of radicals in flames lower than expected based on temperature reduction alone [13], they might be expected to show enhanced performance relative to $\mathrm{CO}_{2}$ when combined with catalytic agents. Figure 3 presents the burning velocity reduction caused by pure $\mathrm{CF}_{3} \mathrm{H}$ addition to the above flames; a mole fraction of about $5 \%$ is required to reduce $\mathrm{S}_{\mathrm{L}}$ by two. Data are also presented for addition of the equivalent of $0.35 \% \mathrm{Fec}$ in $\mathrm{CF}_{3} \mathrm{H}$. Unlike ferrocene addition to $\mathrm{CO}_{2}$, in which $0.35 \% \mathrm{Fec}$ in $\mathrm{CO}_{2}$ reduces the amount of $\mathrm{CO}_{2}$ required by a factor of about five, this amount of ferrocene in $\mathrm{CF}_{3} \mathrm{H}$ reduces the amount of $\mathrm{CF}_{3} \mathrm{H}$ required only by about $25 \%$. This poor performance may be due to reactions between iron species and fluorine which reduce the gas-phase mole fraction of the active iron-species intermediates, effectively poisoning the iron catalyst [5,14].

To further illustrate the synergistic behavior of $\mathrm{Fec}$ with $\mathrm{CO}_{2}$, and the antagonistic behavior of Fec with $\mathrm{CF}_{3} \mathrm{H}$, we examine the performance of the blend relative to individual contributions from each component. We define the normalized flame speed at each inhibitor mole fraction $X_{i n}$ as $\mathrm{N}_{\mathrm{SL}}\left(X_{i n}\right)$, and the reduction in the normalized

\footnotetext{
${ }^{1}$ Certain commercial equipment, instruments, or materials are identified in this paper to adequately specify the procedure. Such identification does not imply recommendation or endorsement by the National Institute of Standards and Technology, nor does it imply that the materials or equipment are necessarily the best available for the intended use.
} 
flame speed as $\mathrm{R}_{\mathrm{SL}}\left(X_{i n}\right)=1-\mathrm{N}_{\mathrm{SL}}\left(X_{i n}\right)$. Assuming that the flame speed reduction of a two-component blend $\left.\mathrm{R}_{\mathrm{SL}}\left(X_{i n}\right)\right|_{\text {blend }}$ is a linear combination of the contribution from each component, $\left.\mathrm{R}_{\mathrm{SL}}\left(X_{i n, 1}, X_{i n, 2}\right)\right|_{\text {blend }}=X_{i n, 1} \mathrm{R}_{\mathrm{SL}, 1}+$ $X_{i n, 2} \mathrm{R}_{\mathrm{SL}, 2}$, the predicted normalized burning velocity of the blend is $\left.\mathrm{N}_{\mathrm{SL}}\left(X_{i n, 1}, X_{i n, 2}\right)\right|_{\text {blend }}=1-\left.\mathrm{R}_{\mathrm{SL}}\right|_{\text {blend }}$. The ratio of the predicted to the actual normalized flame speed for several blends is shown in Figure 4. A value greater than unity shows that the blend provides a reduction in the normalized burning velocity more than expected based on a linear combination of the contribution from each component, while a value less than one shows the converse. In Figure 4, the curve near unity shows the result for a blend of $2 / 1$ molar ratio of $\mathrm{N}_{2}$ to $\mathrm{CO}_{2}$; that is, for thermally acting agents in these flames and in this range of inhibitor mole fraction, the reduction in flame speed from $\mathrm{CO}_{2}$ and $\mathrm{N}_{2}$ is additive. As the figure shows, $\mathrm{CO}_{2}$ with $0.54 \% \mathrm{Fec}$ is significantly more effective than would be expected based on a linear combination of the performance of $\mathrm{Fec}$ and $\mathrm{CO}_{2}$ alone, while $\mathrm{CF}_{3} \mathrm{H}$ and $\mathrm{Fec}$ is significantly less effective than the sum of each individually.

We have presented the first data on ferrocene as a flame inhibitor, and shown it to be as efficient as $\mathrm{Fe}(\mathrm{CO})_{5}$ at reducing the burning velocity of premixed methane flames. The results imply that either agent acts as an effective precursor for the active iron-species intermediates. For the data presented here, ferrocene does not appear to lose its effectiveness as drastically as does $\mathrm{Fe}(\mathrm{CO})_{5}$, and its inhibition has just as strong a dependence on $X_{O 2, o x}$. As a result, blends of $\mathrm{CO}_{2}$ and $\mathrm{Fec}$ show very strong inhibition, overcoming the loss of effectiveness observed for pure $\mathrm{Fec}$ or $\mathrm{Fe}(\mathrm{CO})_{5}$. Further, blends of $\mathrm{CO}_{2}$ and $\mathrm{Fec}$ reduce the burning velocity of premixed methane-air flames more strongly than expected based on the performance of each individually. Blends of $\mathrm{CF}_{3} \mathrm{H}$ and $\mathrm{Fec}$, however, have been found to be much less effective than expected based on the performance of each individually, implying that iron species and halogens may enter into undesired reactions which poison the catalytic cycles. Nonetheless, if means can be identified to safely introduce gas-phase iron compounds into fires, combinations of catalytically and relatively inert thermally acting inhibitors may prove to be an efficient approach to solving a problem which threatens the global environment.

We thank Prof. Dino Megarides of UIC for helpful discussions, and for sending us his ferrocene evaporator. We also thank Dr. Wing Tsang for stimulating conversations and suggestions throughout this research. This research was supported in part by NGP MIPR No. W74RDV83528667.

[1]. Reinelt, D. and Linteris, G.T., Twenty-Sixth Symposium (International) on Combustion, The Combustion Institute, Pittsburgh, 1996, pp. 1421-1428.

[2]. Babushok, V., Tsang, W., Linteris, G.T., and Reinelt, D., Combust. Flame 115:551 (1998).

[3]. Rumminger, M.D., Reinelt, D., Babushok, V., and Linteris, G.T., Combust. Flame 116:207 (1999).

[4]. Rosser, W.A., Inami, S.H., and Wise, H., Combust. Flame 7:107 (1963).

[5]. Hastie, J. W., High Temperature Vapors, Academic Press, New York, 1975.

[6]. Rumminger, M.D. and Linteris, G.T., "An Experimental Study Of The Role Of Particles In Flame Inhibition By Iron Pentacarbonyl," in preparation for submission to Combustion and Flame. 1999.

[7]. Rosser, W. A, Inami, S. H., and Wise, H., Study of the Mechanisms of Fire Extinguishment of Liquid Rocket Propellants, WADC Technical Report 59-206, 1959.

[8]. Lott, J.L., Christian, S.D., Sliepcevich, C.M., and Tucker, E.E., Fire Technology 32:260 (1996).

[9]. Noto, T., Babushok, V., Hamins, A., and Tsang, W., Combust. Flame 112:147 (1998).

[10]. Rumminger, M.D. and Linteris, G.T., "Inhibition of Premixed Carbon Monoxide-Hydrogen-OxygenNitrogen Flames by Iron Pentacarbonyl," submitted to Combustion and Flame, March 1999.

[11]. Linteris, G.T. and Truett, L., Combust. Flame 105:15 (1996).

[12]. Zhang, J. and Megaridis, C.M., Twenty-Fifth Symposium (International) on Combustion, The Combustion Institute, Pittsburgh, 1994, pp. 593-600.

[13]. Linteris, G.T., Burgess, D.R., Babushok, V., Zachariah, M., Tsang, W., and Westmoreland, P., Combust. Flame 113:164 (1998).

[14]. Tsang, W., Personal Communication, April 1999. 


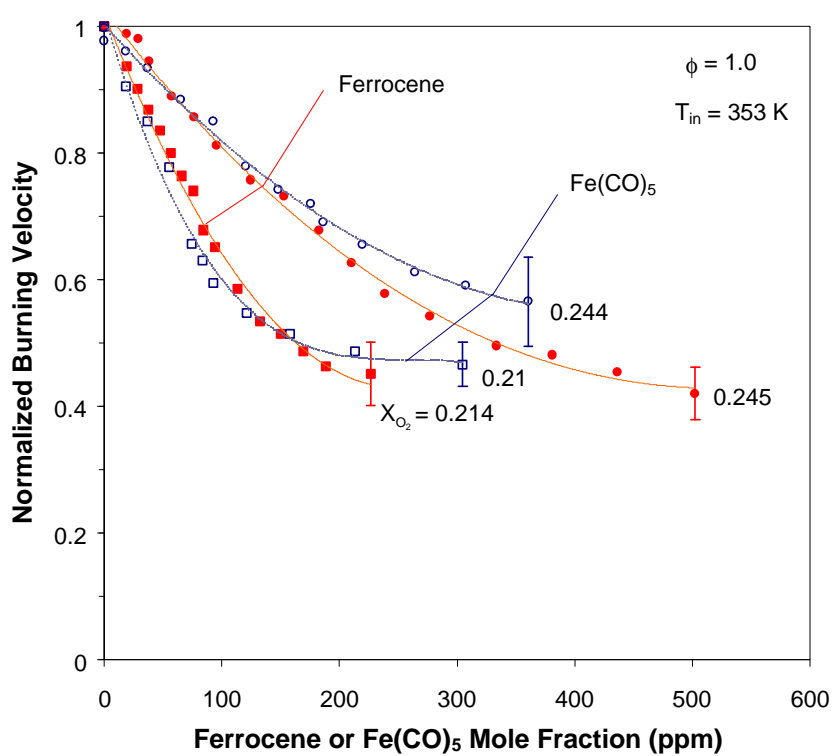

Figure 1 - Normalized burning velocity of premixed $\mathrm{CH}_{4} / \mathrm{O}_{2} / \mathrm{N}_{2}$ inhibited by ferrocene and $\mathrm{Fe}(\mathrm{CO})_{5}$ for several values of the oxygen mole fraction in the oxidizer $X_{O 2, o x}$.

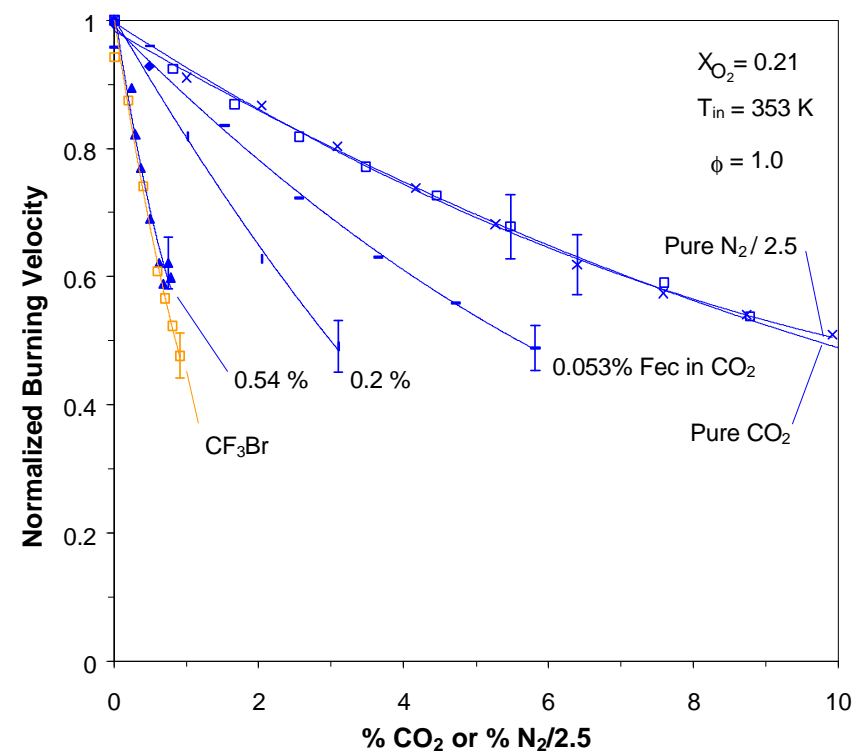

Figure 2 - Normalized burning velocity of $\mathrm{CH}_{4} / \mathrm{O}_{2} / \mathrm{N}_{2}$ flames inhibited by pure $\mathrm{CO}_{2}$ and pure $\mathrm{N}_{2}$, and by blends of $\mathrm{CO}_{2}$ and ferrocene. The equivalent percentage of ferrocene in $\mathrm{CO}_{2}$ is given, and data for $\mathrm{CF}_{3} \mathrm{Br}$ are shown for comparison.

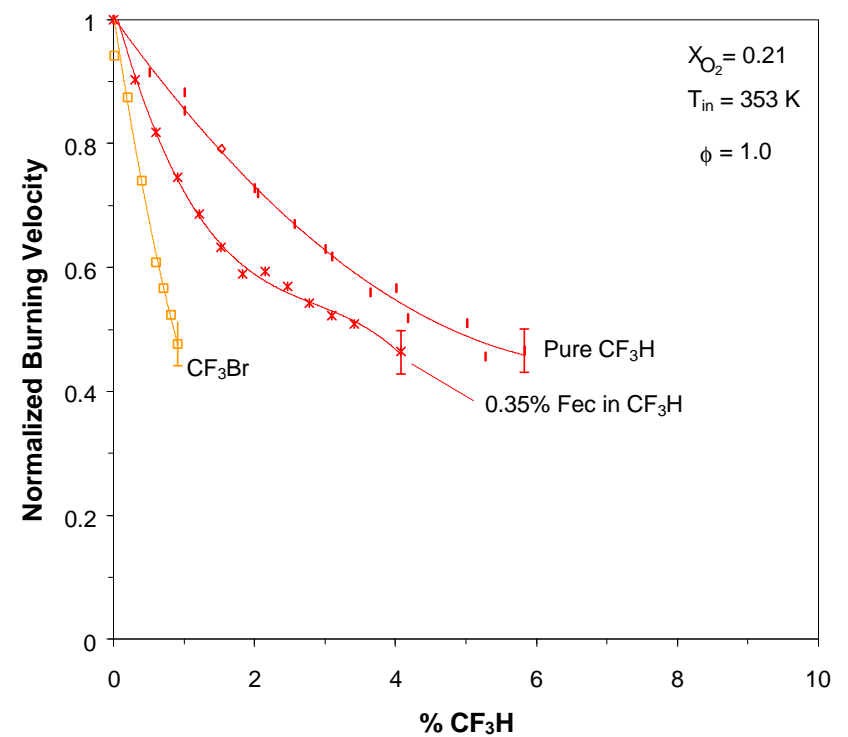

Figure 3 - Normalized burning velocity of premixed $\mathrm{CH}_{4} / \mathrm{O}_{2} / \mathrm{N}_{2}$ flames inhibited by pure $\mathrm{CF}_{3} \mathrm{H}$ and by $\mathrm{CF}_{3} \mathrm{H}$ with $0.35 \%$ ferrocene, together with data for $\mathrm{CF}_{3} \mathrm{Br}$.

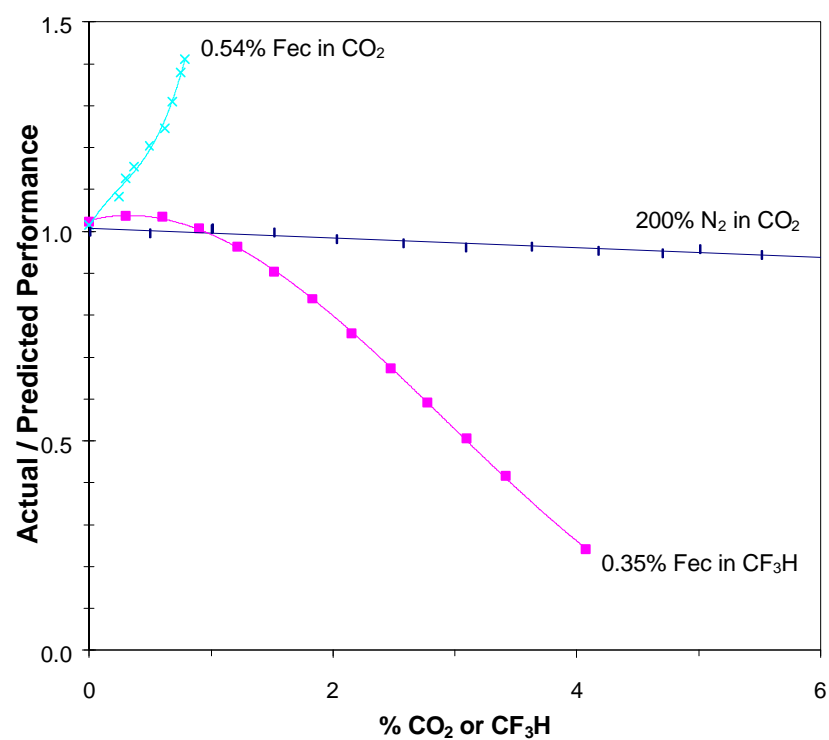

Figure 4 - Index of actual performance of inhibitor blend as compared to the predicted performance based on a linear sum of the burning velocity reduction caused by each component. 